\title{
Boeing 737 MAX: A case study of failure in a supply chain using system of systems framework
}

\author{
Jennifer Kuczynski, The MITRE Corporation, jkuczynski@mitre.org* \\ Chaojie Wang, The MITRE Corporation, cjwang@mitre.org* \\ Marie Glass, The MITRE Corporation,mglass@mitre.org* \\ Fred Hoffman, Mercyhurst University, fhoffman@mercyhurst.edu \\ * The author's affiliation with The MITRE Corporation is provided for identification purposes only and is not intended to convey or \\ imply MITRE's concurrence with, or support for, the positions, opinions, or viewpoints expressed by the author. (C) 2021 The MITRE \\ Corporation. ALL RIGHTS RESERVED.
}

\begin{abstract}
This paper uses the framework and pain points of the System of Systems (SoS) originated and prevalent in Systems Engineering, to investigate the failure of the Boeing 737 MAX. We posit that a supply chain can be investigated as an SoS and that the SoS framework is useful to describe its health status and pain points. We attempt to analyze the Boeing 737 MAX's epic failure and identify potential issues in its supply chain which may have contributed to the tragic accidents and the eventual grounding of the plane. The analysis provides practical insights to help restore the health of the Boeing 737 MAX supply chain and help prevent it from experiencing the same failure again.
\end{abstract}

Keywords: Systems Engineering, Systems of Systems, Supply Chain, Supply Chain Management, Boeing 737 MAX, FAA, Airline, Airplane

\section{Introduction}

The Boeing 737 MAX has been making international headlines since its grounding in March 2019, after two crashes in five months caused 346 deaths. Figure 1 shows the major events in the timeline over the four-year period. The Boeing 737 MAX 8, a fourth generation Boeing 737, first flew on January 29, 2016, gaining Federal Aviation Administration (FAA) certification in March 2017. It entered service in May 2017 when it was delivered to Malindo Air, a carrier owned by Indonesian Lion Air Group headquartered in Malaysia. By November 2020, 387 aircraft of this model were produced and delivered, with 4,039 orders unfulfilled. (Boeing, 2021)

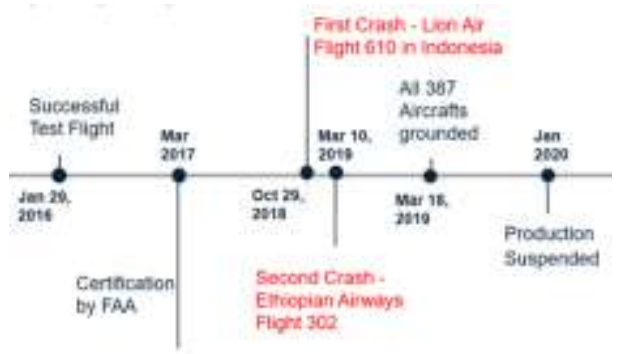

Figure 1. Major timeline of Boeing 737 MAX 


\section{Issues in Information Systems}

Volume 22, Issue 1, pp. 51-62, 2021

\section{Approved for Public Release, Distribution Unlimited. Public Release Case Number 21-0244}

The first crash, Lion Air Flight 610, occurred in Indonesia on October 29, 2018 and killed all 189 people onboard. Preliminary investigations showed a flaw involving the Maneuvering Characteristics Augmentation System (MCAS) which automatically and repeatedly caused the aircraft to nosedive. Pilots had not received training on MCAS and were unable to override the system. In the last communication with the Indonesian Lion Air flight, the pilot had turned over control to the co-pilot while he looked in the manual to decipher how to override MCAS. When it was rolled out, MCAS took readings from only one sensor on any given flight, leaving the system vulnerable to a single point of failure.

The FAA and Boeing issued warnings, but before a fix could be implemented, Ethiopian Airways Flight 302 experienced the same issue. On March 10, 2019, the Ethiopian flight crashed six minutes after takeoff, killing 157 people onboard. Since then, news emerged that multiple pilots had safety concerns about the model's nose pitching down suddenly after engaging the autopilot (a part of the MCAS). ("Boeing 737 MAX", 2019)

Ethiopian Airlines grounded its 737 MAX fleet the same day as the fatal crash, followed the next day by China with many others in quick succession. On March 13, the FAA grounded the airplane, and by March 18, all 387 airplanes were grounded. The grounding of the 737 MAX lasted approximately 20 months and is the longest grounding of any aircraft in US aviation history (FAA, 2020). Boeing suspended production of 737 MAX in January 2020. The FAA did not clear the 737 MAX to fly again until November 2020. In January 2021, the first US passengers flew on the 737 MAX since the grounding; Canada and the Europe announced also in January, that they would begin flying the model again (Chokshi, 2020; Victor, 2021; Hollinger, 2021).

Most previous airplane groundings were based on hardware problems. The 737 MAX was unusual in that a significant part of the issue was related to the software, not hardware. A software malfunction was blamed for the incidents, with nose dives connected to an automated flight control system that acted on flawed information.

The two downed planes did not contain two of the optional features - an angle of attack indicator and a disagree light. One of the optional upgrades, the angle of attack indicator, displayed the readings of the two sensors. The other, called a "disagree light", is activated if those sensors are at odds with one another. After the first crash, Boeing was working on standardizing the disagree light. The jet's software system took readings from one of two vane-like devices called angle of attack sensors that determined how much the plane's nose is pointing up or down relative to oncoming air. When MCAS detects that the plane is pointing up at a dangerous angle, it would automatically push down the nose of the plane to prevent the plane from stalling. Boeing's optional safety features, in part, could have helped the pilots detect any erroneous readings. Of the US airlines, only two had these optional features: Southwest and American Airlines purchased both indicators. United did not purchase either (Tabuchi \& Gelles, 2019).

There were additional reports of other software errors and faulty wiring (Root, 2020), which delayed the recertification of the 737 MAX. Another apparent issue was the lack of knowledge of the MCAS and trim wheel by the pilots, and a key lack of training, as pilots certified in the 737 plane didn't require an update to fly the MAX (as regulators didn't deem it a new type of plane). Boeing has recently recommended full simulator training for all MAX pilots, likely addressing MCAS and trim wheel issues.

Although software defects and insufficient pilot training have been blamed for the two accidents and the loss of hundreds of lives, this paper goes beyond technology and applies the Systems of Systems (SoS) 


\section{Issues in Information Systems}

Volume 22, Issue 1, pp. 51-62, 2021

engineering approach to look deeper and wider within the Boeing 737 MAX supply chain. Technology is only one aspect of the whole in any organization or human endeavor. People and processes are as important, if not more important, than technology. SoS framework provides a holistic approach and helps to identify potential weaknesses and breakdowns that might have existed in the supply chain which may have prevented the technical issues from being addressed and the tragedies being avoided. Using SoS pain points as a framework, this paper summarizes lessons learned and recommends best practices to help the industry recover from the failure, improve its safety and public trust, and mitigate against the possible recurrence of such catastrophic, fatal errors.

\section{SoS characteristics and pain points}

The concept of System of Systems (SoS) grew from the concept of a system. The father of General Systems Theory, von Bertalanffy (1969), believed that "we must think in terms of systems of elements in mutual interaction" (p. 45). Sauser \& Boardman (2007) believed 'togetherness' is the essence of a system because it draws "together ... various parts and the relationships they form in order to produce a new whole" (p. 2).

In summary, a system consists of closely coupled, interconnecting components. Each individual component is typically not functional and useful in and of itself. The components depend on each other and on the encompassing system to provide the necessary structure and organization. There are numerous examples of systems including both natural systems such as plants, animals, and human bodies, and engineered systems such as buildings, computers, and airplanes.

While closely coupled systems are found everywhere, there are also examples of larger and complex sociotechnical systems that consist of loosely coupled and independently operated systems that lack a central command and control mechanism. For example, the Internet consists of numerous independent networks, storages, servers, workstations, and mobile devices without a centralized control. An online community consists of many diverse and independent individuals who communicate and collaborate on a voluntary basis. This leads to the concept of System of Systems (SoS). Jamshidi (2008, p. 5) defined SoS as "large-scale integrated systems which are heterogeneous and independently operable on their own but are networked together for a common goal."

ISO/IEC/IEEE 21839 (International Standards Organization, 2019) defines SoS as a "set of systems or system elements that interact to provide a unique capability that none of the constituent systems can accomplish on its own" (p. 2). It also noted that "each constituent is a useful system by itself, having its own development, management goals and resources, but interacts within the SoS to provide the unique capability of the SoS" (p. 2).

Maier (1998) established the five major characteristics of an SoS. They are summarized as follows:

- Operational Independence - Constituent systems are independent and able to operate without dependency on other constituent systems or the existence of the encompassing SoS.

- Managerial Independence - Constituent systems are governed by their own rules rather than by external ones when they are participating in an SoS.

- Geographical Distribution - Constituent systems are dispersed geographically or virtually; hence, they rely on some form or facility of communication to share their operations results with each other.

- Evolutionary Development - An SoS can be under constant change due to evolution in its purpose and mission. For example, market conditions can change business strategies, resulting in changes of missions. Each constituent system can also undergo its own developmental process. 


\section{Issues in Information Systems}

Volume 22, Issue 1, pp. 51-62, 2021

- Emergent Behaviour - The behaviors of an SoS emerge as a result of the synergistic collaboration of its constituent systems.

Boardman and Sauser (2006) further synthesized prior work by other researchers and proposed a new model to characterize SoS using easy-to-remember mnemonics as summarized here:

- Autonomy - Each constituent system is autonomous in the process of fulfilling the purpose and mission of the SoS. This covers Maier's first two characteristics: Operational and Managerial Independence.

- Belonging - Each constituent system chooses to belong on a cost/benefit basis; each aims to advance its own causes at the same time benefit the larger mission of the SoS. The Maier model does not explicitly include this characteristic.

- Connectivity - Constituent systems communicate, coordinate, and cooperate with each other to share information and knowledge in order to advance their own goals and the goals of the SoS. The Maier model does not explicitly include this characteristic.

- Diversity - Each constituent system is unique and has unique capabilities to augment each other and contribute to the SoS. This covers Maier's Geographical Distribution but goes beyond to include any type of diversity such as virtual, organizational, service, etc.

- Emergence - New and novel capabilities and behaviors emerge through the released autonomy, committed belonging, open connectivity, and collaborative diversity. This covers Maier's Emergent Behaviour characteristic.

Unlike a system which enjoys closeness or togetherness of its components or elements and has higher degree of control over their behaviors and interactions, an SoS faces many challenges in maintaining its operational stability and achieving its common goals due to the autonomous and diverse nature of its constituent systems. Dahmann (2014) identified seven pain points of an SoS along with relevant questions for each challenge area as shown in Table 1:

Table 1. SoS Challenge Areas or Paint Points (Dahmann, 2014)

\begin{tabular}{|l|l|}
\hline SoS Challenge Area/Pain Point & Relevant Questions to Ask and Answer \\
\hline SoS Authorities & What are effective collaboration patterns in SoS? \\
\hline Leadership & What are the roles and characteristics of effective SoS leaders? \\
\hline $\begin{array}{l}\text { Constituent Systems' } \\
\text { Perspectives }\end{array}$ & What are effective approaches to integrating constituent systems? \\
\hline Capabilities and Requirements & How to address SoS capabilities and requirements \\
\hline $\begin{array}{l}\text { Autonomy, Interdependencies } \\
\text { and Emergence }\end{array}$ & $\begin{array}{l}\text { How to address the complexities of interdependencies } \\
\text { and emergent behaviors }\end{array}$ \\
\hline Testing, Validation, and Learning & $\begin{array}{l}\text { How to approach SoS validation, testing, and continuous learning } \\
\text { in SoS }\end{array}$ \\
\hline SoS Principles & What are the key SoS thinking principles? \\
\hline
\end{tabular}




\section{Issues in Information Systems}

Volume 22, Issue 1, pp. 51-62, 2021

The SoS characteristics along with its pain points provide both a theoretical framework and practical guidance to address challenges in developing and managing complex sociotechnical SoS's.

\section{Supply chain as an SoS}

The concept of Supply Chain (SC) and the related concept of Supply Chain Management (SCM) grew from the traditional concept of business logistics and operations management. Since the world entered the era of globalization during the 1980's, more and more businesses have gone international by sourcing and selling products and services from and to the global markets. While globalization helps firms reduce costs and increase sales, it also introduces the complexity and challenges inherent in the global supply chain. The discipline of SCM provides a theoretical foundation and practical guidance to help firms manage the complexity and challenges of globalization.

The SoS framework and its pain points are useful to analyze supply chain. Ghadge, Samir, and Kalawsky (2013) believed that it is necessary to look at supply chain systems from a system of systems perspective. Choi, Cai, and Shen (2019) used an SoS approach to analyze the SCM of the fashion industry. Mrabet, Souissi, and Tikito (2017) conducted a literature review of relevant definitions of SC. They observed how the definition of SC evolved around the concept of a "set of networks", "set of entities", and "complex systems" which bears remarkable similarity to the concept of SoS and concluded that SoS is a suitable framework to model a supply chain.

We applied the five characteristics of SoS identified by Boardman and Sauser's (2008) to SC and described their applicability in Table 2:

Table 2. The Application of SoS Characteristics in SCM

\begin{tabular}{|l|l|}
\hline $\begin{array}{l}\text { SoS Characteristics } \\
\text { (Boardman \& Sauser, } \\
\text { 2008) }\end{array}$ & \multicolumn{1}{|c|}{ Applicability to Supply Chain Management } \\
\hline Autonomy & $\begin{array}{l}\text { All participating organizations are independent from each other, have } \\
\text { only a loose bond, and collaborate only when it is in their self-interest to } \\
\text { do so. }\end{array}$ \\
\hline Belonging & $\begin{array}{l}\text { A supply change establishes a set of governing rules and processes so that } \\
\text { the diverse and autonomous participants can share common goals of } \\
\text { commerce, trade, and mutual benefits. }\end{array}$ \\
\hline Connectivity & $\begin{array}{l}\text { Participants connect, communicate, collaborate, and coordinate to achieve } \\
\text { the common goals and self-interests. }\end{array}$ \\
\hline Diversity & $\begin{array}{l}\text { Participants bring a diverse set of services, products, knowledge, skills, } \\
\text { and even diverse cultures and systems to the supply chain. }\end{array}$ \\
\hline Emergence & $\begin{array}{l}\text { Innovations and interruptions emerge from the activities and } \\
\text { collaborations due to the diverse and autonomous nature of each } \\
\text { participant. }\end{array}$ \\
\hline
\end{tabular}

The SoS pain points developed by Dahmann at el. (2014) can be applied to SC. We summarize this applicability in Table 3: 


\section{Issues in Information Systems}

Volume 22, Issue 1, pp. 51-62, 2021

Table 3. The Application of SoS Pain Points in Supply Chain Management

\begin{tabular}{|l|l|}
\hline $\begin{array}{l}\text { SoS Challenges/Pain Points } \\
\text { (Dahmann, 2014) }\end{array}$ & Related Supply Chain Issues \\
\hline SoS Authorities & $\begin{array}{l}\text { There is lack of a central authority that can direct or control all } \\
\text { other participants. The SC relies heavily on all participants to } \\
\text { follow the agreed protocols, processes, and procedures. }\end{array}$ \\
\hline Leadership & $\begin{array}{l}\text { All participants must lead without authority and power in the } \\
\text { common interests of the group. }\end{array}$ \\
\hline Constituent Systems' Perspectives & $\begin{array}{l}\text { Each participant has its own interests and perspectives. They } \\
\text { participate with their interests first and the interests of others and } \\
\text { the common interests second. }\end{array}$ \\
\hline Capabilities and Requirements & $\begin{array}{l}\text { Each participant must bring to the network its unique capabilities } \\
\text { that benefit other participants and the common goals. Not only } \\
\text { must the requirements for each participant's products and } \\
\text { services be met timely and with quality, but the capabilities of all } \\
\text { participants must also be integrated in order to achieve the } \\
\text { common mission. The integration is much harder in an SoS than } \\
\text { in a system where there is a central command and control. }\end{array}$ \\
\hline $\begin{array}{l}\text { Autonomy, Interdependencies and } \\
\text { Emergence }\end{array}$ & $\begin{array}{l}\text { The diversity and autonomy of all participants along with their } \\
\text { interaction and collaboration can lead to innovations and } \\
\text { sometimes disruptions. }\end{array}$ \\
\hline Testing, Validation, and Learning & $\begin{array}{l}\text { The final product or outcome must be thoroughly tested and } \\
\text { validated before it is delivered to the end user. While the } \\
\text { responsibility of quality and delivery rests upon the product } \\
\text { owner, the validation of quality requires the concerted effort of } \\
\text { all participants. }\end{array}$ \\
\hline
\end{tabular}

\section{Analysis using the SoS framework}

While Boeing produces the 737 MAX in its plant in Washington State, US, it has more than 600 suppliers, many of which also rely on their own suppliers to deliver various products and services. A list of more than 900 companies was included in the settlement that Indonesian airline Lion Air offered to families of the victims of the October 2018 crash (MacMillan \& Gregg, 2019). The 737 MAX is a globally made airplane; the components are manufactured in factories around the world, and are then assembled at Boeing's facility in Renton, Washington.

In addition to hundreds of suppliers, the FAA also plays a key role in the Boeing 737 MAX supply chain. The FAA is the federal agency responsible for the regulation and certification of commercial and private aircraft. It ensures the planes are safe to fly on the behalf of the millions in the global flying public. The supply chain also includes Boeing's direct customers (the airlines) and indirect customers (the flying public). Figure 2 is a high-level depiction of the Boeing supply chain as an SoS. In this loosely coupled supply chain SoS, all parties are independent and yet interdependent; they share common goals of comfortable, economical, and safe flights, and yet each has its own interests which are not completely aligned with the common goals. There is no central authority to direct activities and exert leadership. Participation is voluntary. Collaboration becomes imperative for achieving the common goals. 


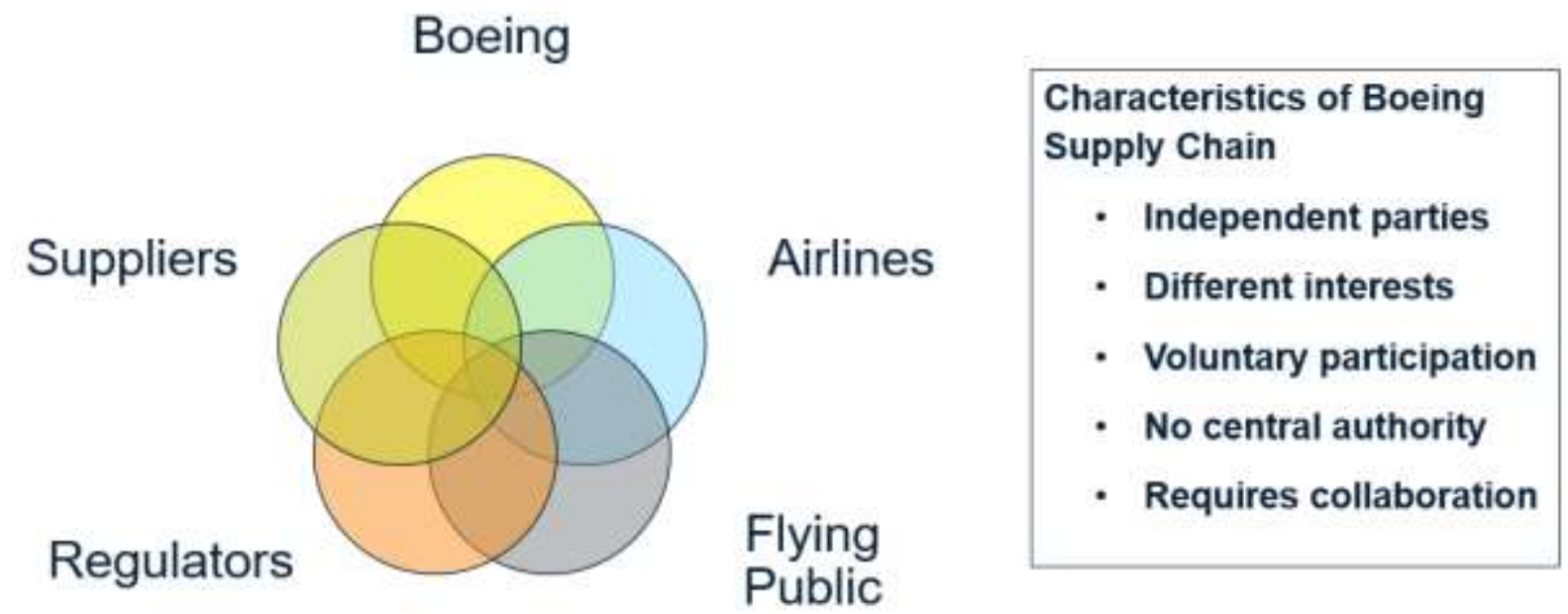

Figure 2. High-level View of Boeing 737 MAX Supply Chain

Table 4 summarizes our findings of issues/weaknesses in Boeing 737 MAX supply chain using the SoS framework and its pain points. This is followed by a more detailed analysis of each pain point.

Table 4. Issues and Weaknesses in Boeing 737 MAX Supply Chain

\begin{tabular}{|c|c|}
\hline SoS Pain Points & Boeing 737 MAX SC Issues and Weaknesses \\
\hline SoS Authorities & $\begin{array}{l}\text { While the FAA does not have command and control over its SC, it does play the key role of } \\
\text { a regulator to certify the safety of the plane. However, the FAA's 'delegate' system allows } \\
\text { Boeing to self-certify and self-police which can put corporate profit over public safety. }\end{array}$ \\
\hline Leadership & $\begin{array}{l}\text { The SC looks to each participant to make decisions that aim at the common goals of public } \\
\text { safety. However, when there are conflicts between a participant's own goals and common } \\
\text { goals, a participant tends to prioritize their own goals over the common goals. The lack of } \\
\text { leadership from a centralized authority makes the common goals untenable in the face of } \\
\text { conflicts. }\end{array}$ \\
\hline $\begin{array}{l}\text { Constituent } \\
\text { Systems' } \\
\text { Perspectives }\end{array}$ & $\begin{array}{l}\text { Boeing's decisions were predominantly driven by concerns about profitability. As a for- } \\
\text { profit business, it answers to its shareholders and the safety and priority of the flying public } \\
\text { became secondary. } \\
\text { - Boeing decided to move the engines on the } 737 \text { MAX forward to save costs. } \\
\text { - } \text { Boeing decided to accept a single point of failure on MCAS design to save costs. } \\
\text { This helps Boeing shorten the certification time and help airlines reduce pilot } \\
\text { training cost. } \\
\text { Boeing decided to make the two safety features optional. Both Lion Air and } \\
\text { Ethiopian Airways did not purchase either safety option to save cost. }\end{array}$ \\
\hline $\begin{array}{l}\text { Capabilities and } \\
\text { Requirements }\end{array}$ & $\begin{array}{l}\text { Due to Boeing's cost cutting design decisions, the } 737 \text { MAX had reduced capabilities and } \\
\text { became less safe which eventually led to the tragic accidents. }\end{array}$ \\
\hline $\begin{array}{l}\text { Autonomy, } \\
\text { Interdependencies } \\
\text { and Emergence }\end{array}$ & $\begin{array}{l}\text { Boeing made design decisions to save costs without sufficient deliberation, inputs, and } \\
\text { consensus from the airlines and FAA. Collaborations help lead to better relationships and } \\
\text { better decisions while isolations contribute to frictions and uninformed or even dangerous } \\
\text { decisions. }\end{array}$ \\
\hline $\begin{array}{l}\text { Testing, } \\
\text { Validation, and } \\
\text { Learning }\end{array}$ & $\begin{array}{l}\text { FAA delegated the certification of aircrafts to the manufacturer. The delegation system was } \\
\text { criticized, and its effectiveness was questioned while DOT/FAA continued to defend it. } \\
\text { Boeing outsourced software development to contract companies and failed to conduct } \\
\text { rigorous testing and validation. Pilot training was also insufficient. }\end{array}$ \\
\hline
\end{tabular}




\section{Issues in Information Systems}

Volume 22, Issue 1, pp. 51-62, 2021

\section{SoS Authorities}

The Boeing 737 MAX story is one where critical information was inadequately shared, willfully concealed, or inadequately understood when it was shared (House Committee, 2020, p. 13). For example, documentation revealed that at least four Boeing Authorized Representatives (ARs) had been aware of a 2012 incident where a Boeing 737 MAX test pilot took more than 10 seconds to respond to an MCAS activation in a flight simulator, a condition the pilot found to be catastrophic (House Committee, 2020, p. 15). However, investigators could find no evidence "that any of these ARs informed the FAA about this critical test data" (House Committee, 2020, p. 115). "Even the most senior leadership of Boeing's 737 MAX program were unaware of the 10-second reaction time issue" (House Committee, 2020, p. 116).

Sgobba (2019) notes that while the outward appearance of civilian passenger jets has changed very little over the past half century, the technological changes inside these aircraft have been enormous, resulting in an "ever-widening skill gap between regulators and industry" (p. 299). However, while the technology and engineering advances have changed rapidly, the rules and processes for certifying a civil aircraft "have not changed very much over the last 70 years" (Sgobba, 2019, p. 300). Sgobba's (2019) observation may explain why Michael Teal, Vice President, Chief Project Engineer, and Deputy Program Manager of the 737 MAX program, "approved the design of MCAS despite being unaware of basic facts about the system," such as the fact that MCAS "relied on a single sensor" (House Committee, 2020, p. 116).

\section{Leadership}

Leadership in Boeing and the FAA had very different organizational objectives: Boeing's objectives were the retention of market share through rapid, on-schedule aircraft production and the minimization of costs, an outgrowth of what Catchpole (2020) referred to as Boeing's "shareholder-first culture" (p. 1). The FAA's objectives, however, were to ensure that Boeing designed and produced safe, certifiable aircraft (Sgobba, 2019). To keep costs down, Boeing downplayed the criticality of the MCAS system in order to avoid the requirement for simulator training for customer pilots transitioning to the new $737 \mathrm{MAX}$. If simulator training had been needed, Boeing "would have owed Southwest (Airlines) between $\$ 200$ to nearly $\$ 400$ million" dollars (House Committee, 2020, p. 24). "Boeing not only discounted concerns from its own engineers that in hindsight proved remarkably pertinent to improving the safety of the 737 MAX, but it also did not share certain information about what it knew about MCAS with regulators, and it chose not to inform the vast majority of MAX pilots about the very existence of MCAS" (House Committee, 2020, p. 118). Although Boeing presented MCAS "as a stability enhancing system, the MCAS' ultimate function is to prevent stall, one of the most dangerous phenomena in aviation" (Sgobba, 2019, p. 299).

\section{Constituent Systems' Perspectives}

Airbus's introduction of its fuel-efficient A320neo airliner threatened Boeing's share in the fuel efficient, single-aisle passenger aircraft market. As Seyer and Londner (2020) noted, Boeing found itself needing to "offer an aircraft that would ultimately save airlines training cost and times to ensure they could challenge Airbus" (p. 99). The need to rapidly produce the 737 MAX aircraft not only stressed Boeing management, but also its production line workers.

On 9 June 2018, Ed Pierson, a retired naval officer serving as Senior Manager for Production System Support for the Boeing 737's final assembly program, emailed Scott Campbell, the General Manager of the 737 program and most senior Boeing official at the Renton, WA facility where the $737 \mathrm{~s}$ were being produced. In that email, Pierson expressed safety concerns that the pressure to produce on-schedule was exhausting Boeing production line employees, causing them to circumvent production processes (House 


\section{Issues in Information Systems}

Volume 22, Issue 1, pp. 51-62, 2021

Committee, 2020). It took Pierson five weeks to meet with Campbell in person and urge temporarily ceasing operations due to safety concerns, a standard practice in the military (House Committee, 2020). According to Pierson, Campbell rebuffed him by pointing out that the military does not operate for profit.

Three months later, Lion Air flight 610 crashed (House Committee, 2020). On 12 March 2019, two days after the Ethiopian Airlines crash, the second fatal 737 MAX catastrophe, Pierson wrote to the Boeing Board of Directors and complained that his previously stated safety concerns derived from "senior leadership actions/inactions, schedule pressure, overworked employees, understaffing, process deviations, supplier and quality issues" (House Committee, 2020, p. 182). No one from Boeing responded to Pierson's letter (House Committee, 2020). According to the House Committee (2020) report, Pierson's experience with Boeing leadership "paints a deeply troubling picture of Boeing's production first, safety second, culture among Boeing's senior leadership" (p. 187).

\section{Capabilities and Requirements}

A core problem with the MCAS and Angle of Attack (AOA) indicator issues was that Boeing leadership was torn between the engineering need for adding these systems while at the same time denigrating their importance to avoid having to provide costly simulator training for pilots transitioning to the new aircraft (House Committee, 2020). In short, Boeing subordinated engineering and safety requirements to its business imperatives. The price for this crucial mistake was first paid for by Lion Air pilot Bhavye Suneja, an experienced 737 pilot with over 6,000 hours of flying time, who "lacked a crucial piece of information" (Ellis, 2019, p. 5) that caused him to crash his aircraft into the Java Sea, killing all 189 people aboard.

\section{Autonomy, Interdependencies and Emergence}

In an SOS structure, autonomous entities have interdependent relationships, with each entity having distinct roles and responsibilities. In the $737 \mathrm{MAX}$ case, the roles and responsibilities of three distinct groups were not properly exercised. The House Committee report (2020) identified the groups of players involved in the 737 MAX certification process as: Boeing employees, Boeing Authorized Representatives (AR), and employees of the FAA. While the organizational interests of the Boeing representatives and FAA employees are self-evident, those of the ARs were less so. ARs were Boeing employees who were "granted special permission to represent the interests of the FAA and to act on the agency's behalf in validating aircraft systems and designs' compliance with FAA requirements" (House Committee, 2020, p. 14). Although ARs were responsible for making the FAA aware of safety issues, there were instances where ARs did not report important safety information to the FAA, and where AR-reported concerns about MCAS activation issues were "not thoroughly investigated or dismissed" by Boeing employees (House Committee, 2020, p. 14). In addition, the House Committee report (2020) pointed to instances where FAA leadership overruled conclusions reached by FAA technical experts "at the behest of Boeing" (14). "From FAA leadership down, ineffective communication and lack of coordination on key certification and safety issues jeopardized the safety of the flying public" (House Committee, 2020, p. 16).

\section{Testing, Validation, and Learning}

Training had long been a Boeing hallmark, dating back to the College of Jet Knowledge the company established when it introduced its 707 Airliner in the 1950s (Ellis, 2019). In 2016, Boeing CEO Dennis Muilenberg pledged to double Boeing's profit margins (Catchpole, 2019). Boeing's shift to being a more profit-oriented company negatively impacted its longstanding emphasis on pilot training. "Boeing's efforts to turn pilot training into a profitable business may have hindered staff cooperation that could have detected the 737 Max's design flaws before it entered service" (Ellis, 2019. p. 5). Not requiring transitioning pilots 


\section{Issues in Information Systems}

Volume 22, Issue 1, pp. 51-62, 2021

to undergo simulator training in the 737 MAX proved to be a calamitous mistake. Boeing acted "as if the interaction between human and automatic system is the same as human and conventional mechanical or electrical instrument, and as if making a software 'safe' is solely a matter of process quality control" (Sgobba, 2019, 302).

\section{Summary}

An SoS framework along with its pain points was used to analyze the Boeing 737 MAX supply chain and illuminate the issues and weaknesses that may have contributed to its failure to prevent the recent tragic accidents. The lack of leadership from a central authority is the most significant pain point of an SoS as an SoS consists of loosely coupled, diverse, and autonomous systems. It is the nature of an SoS that constituent systems are independent of each other and are autonomous in goals, management, operations, and decision making. To achieve common SoS Goals, each constituent system must align its own goals with the common goals and make decisions that do not deviate from the common goals. In the event of conflicts of interests, constituent systems must collaborate and deliberate to ensure sensible and optimal solutions can be found, and outcomes can be achieved that benefit the larger SoS as a whole.

The key issue in the case of the Boeing 737 MAX supply chain is the conflict between corporate profitability and public safety. The corporate profits and shareholder earnings outweighed the public safety when Boeing made its design decisions. The cost savings measures prevented the adoptions of safer and more effective technical designs. Governments and regulators would have had a positive impact if they had exercised more judicially their oversight responsibilities. However, in the case of the Boeing 737 MAX, this was not the case. In a tightly regulated industry such as aerospace and aviation, government plays a key role and must be recognized as a constituent system in the supply chain SoS. In addition, government can also be viewed as a proxy to consumers and represent the public interest. The FAA, as a constituent system, would have played a crucial role to mediate the conflicts and to ensure public safety was not jeopardized by dangerous cost saving decisions made by Boeing, by exercising stronger oversight and following a more rigorous certification process.

\section{References}

Bertalanffy, Ludwig von. (1969). General system theory; foundations, development, applications. New York, NY: G. Braziller

Boardman, J., \& Sauser, B. (2006). System of Systems-the meaning of of. Procedings of the 2006 IEEE/SMC International Conference on Systems of Systems Engineering, (April), 118-123. https://doi.org/10.1109/SYSOSE.2006.1652284

Boeing (2021). Orders \& Deliveries. Retrieved Januray 5, 2021 from https://www.boeing.com/commercial/\#/orders-deliveries

Boeing 737 MAX aircraft grounded after crashes (2019). Risk Management, 66(5). Retrieved January 5, 2021 from

https://search.proquest.com/openview/f95edc3b0b84eddc475276b632beb4ae/1?cbl=47271\&pqorigsite $=$ gscholar

Catchpole, D. (2020). Boeing's long descent. Fortune, 56-63.

Choi, T. M., Cai, Y. J., \& Shen, B. (2019) Sustainable Fashion Supply Chain Management: A System of Systems Analysis. IEEE Transactions on Engineering Management, 66(4), 730-745 


\section{Issues in Information Systems}

Volume 22, Issue 1, pp. 51-62, 2021

Chokshi, N. (2020). Boeing 737 Max Resumes Flying U.S. Passengers After 2-Year Halt. Retrieved January 22, 2021, from https://www.nytimes.com/2020/12/29/business/boeing-737-maxreturn.html

Dahmann, Judith. (2014). Systems of systems: perspectives, pain points and prospects. Retrieved December 27, 2020, from: http://sosengineering.org/2014/wp-

content/uploads/2014/05/Dahmann-SoSE-Adelaide-Keynote-final.pdf

Ellis, J. E. (2019). Where the 737 went off course. Bloomberg Businessweek, 1-6.

FAA (2020). FAA Updates on Boeing 737 MAX. Retrieved January 13, 2021 from https://www.faa.gov/news/updates/?newsId=93206

Final Committee Report: The design, development \& certification of the Boeing 737 MAX. (2020). Committee on Transportation and Infrastructure, U.S. House of Representatives. Washington, DC, $1-245$.

Ghadge, A, Samir, D., \& Kalawsky, R.S. (2013). A systems approach for modelling supply chain risks. Supply Chain Management, 18(5, 523-538.

Hollinger, P. (2021). Boeing 737 Max recertified to fly in Europe from next week. Retrieved January 22, 2021, from https://www.ft.com/content/4bc07cfe-f428-49db-95df-6bb45dba1b9d

International Standards Organization. (2019). System of Systems (SoS) Considerations in Life Cycle Stages of a System. Retrieved December 27, 2020, from

https://ieeexplore.ieee.org/stamp/stamp.jsp?arnumber=8767116

Jamshidi, M. (2008). System of systems engineering - New challenges for the 21 st century. IEEE Aerospace and Electronic Systems Magazine. https://doi.org/10.1109/MAES.2008.4523909

MacMillan, D., Gregg, A. (2019). Boeing's 737 Max design contains fingerprints of hundreds of suppliers.

The Washington Post. Retrieved January 5,2021, from https://www.washingtonpost.com/business/economy/boeings-737-max-design-containsfingerprints-of-hundreds-of-suppliers/2019/04/05/44f22024-57ab-11e9-8ef3fbd41a2ce4d5_story.html

Mrabet, W., Souissi, N., \& Tikito, K. (2017). Definitions of Supply Chain: Evolution toward System of Systems. 10th International Colloquium of Logistics and Supply Chain Management. ENSIAS, Rabat, Morocco.

Maier, M. W. (1998). Architecting principles for systems-of-systems. Systems Engineering, 1(4), 267284.

Root, A. (2020). These 6 issues are preventing the Boeing 737 MAX from flying. Barron's. Retrieved Jan 5, 2021, from https://www.barrons.com/articles/these-6-issues-are-preventing-the-boeing-737max-from-flying-51580752481 


\section{Issues in Information Systems}

Volume 22, Issue 1, pp. 51-62, 2021

Sauser, B., Boardman J. (2007) Complementarity: in search of the biology of systems. Procedings of the 2007 IEEE International Conference on System of Systems Engineering, San Antonio, TX.

Seyer, K., \& Londner, E. (2020). Case study of the Boeing 737 MAX 8 crashes using a systems thinking approach. Proceedings of the 2020 Annual General Donald R. Keith Memorial Capstone Conference, West Point, NY, April 30, 2020, p. 93-100.

Sgobba, T. (2019). B-737 MAX and the crash of the regulatory system. Journal of Space Safety Engineering, 6(4), 299-303.

Tabuchi, H., \& Gelles, D. (2019). Doomed Boeing Jets Lacked 2 Safety Features That Company Sold Only as Extras. Retrieved January 22, 2021, from https://www.nytimes.com/2019/03/21/business/boeing-safety-features-charge.html

Victor, J. (2021). Canada to lift Boeing 737 MAX flight ban on Jan. 20. Retrieved January 22, 2021, from https://www.ctvnews.ca/business/canada-to-lift-boeing-737-max-flight-ban-on-jan-20-1.5271231 